\title{
Criminal responsibility in Sri Lanka: a descriptive study of forensic psychiatric assessments in remand prisoners charged with murder and related crimes
}

\author{
Neil Fernando, Angelo De Alwis, Wajantha Kotalawala
}

\section{Background}

Persons of 'unsound mind' are absolved of responsibility for criminal acts under provisions of the penal code of Sri Lanka. However, being diagnosed with a mental illness does not automatically absolve persons from criminal responsibility. There is no published data about criminal responsibility among offenders with mental illness in Sri Lanka

Aims

The study aims to determine the proportion of patients who were deemed to be of unsound mind among those admitted for psychiatric assessment to the forensic psychiatry unit of a tertiary care centre for mental health.

Methods

A retrospective study was carried out on patients who were charged with murder, culpable homicide or for being an accomplice to murder and were admitted to the tertiary care center for a forensic psychiatric assessment over a period of one year. Data was collected from court reports and clinical records.
Results

Forty two persons were assessed (38 males, 4 females) during this period. Among them, 37 (88\%) were diagnosed as having a mental illness. The commonest diagnosis was schizophrenia, seen in $23(62.1 \%)$ patients. Of the 37 patients diagnosed with a mental illness, 13 (35.1\%) were deemed to have had 'unsound mind' at the time of the alleged offence. Twelve patients (32.4\%) diagnosed with mental illness were found to have a 'sound mind'. In $13(30.9 \%)$ patients, the mental state at the time of the alleged crime could not be determined due to the lack of information.

Conclusions

Forensic psychiatric assessments lead to a significant number of mentally ill offenders to being declared as being of 'unsound mind' due to mental illness. A delay in the assessment limits the ability of the psychiatrist to provide an opinion on criminal responsibility.

SL J Psychiatry 2012; 3 (1):28-29

\section{Introduction}

Being of 'unsound mind', as defined in the penal code of Sri Lanka, absolves persons from responsibility for criminal acts. Section 77 of the penal code states that: "Nothing is an offence which is done by a person who, at the time of doing it, by reason of unsoundness of mind, is incapable of knowing the nature of the act or that he is doing what is either wrong or contrary to law"(1). This is based on the legal principle that without a 'criminal intent' there is no 'crime'. This suggests that the act must be voluntary and that there must be mental capacity to form an intent which forms the basis of the crime.

If courts have reason to believe that a defendant is suffering from a mental illness, psychiatrists may be requested to assess the state of mind of the defendant at the time of the alleged offence. Based on this assessment, the psychiatrist may be required to provide an opinion on the legal accountability of the defendant ('criminal responsibility') to courts. The results of the assessment may have a major impact on the verdict of a trial (2). Those with a psychiatric diagnosis may be deemed to be of 'unsound mind' and thus not criminally responsible for the crime. However a diagnosis of a mental illness does not always absolve a person from criminal responsibility. The psychiatric assessment helps to determine criminal responsibility by attempting to reconstruct the mental state of the accused at the time of committing the alleged offence.

In Sri Lanka, the prescribed punishment for murder in the Penal Code is the death penalty (3). In practice, this is usually converted to a life sentence. Thus the assessment of an accused charged with murder has a significant impact.

The objective of this study was to determine the proportion of patients who were deemed to be of unsound mind among those admitted for psychiatric assessment to a forensic psychiatry unit of a major tertiary care centre for mental health in Sri Lanka.

\section{Method}

The study was retrospective and carried out on patients who were charged with murder, culpable homicide or for being an accomplice to murder and were admitted for a psychiatric assessment to the forensic psychiatry unit at the National Institute of Mental Health, Anogoda which received patients from prisons throughout the country. Data was collected from court reports and clinical records.

A questionnaire specifically designed for this study was used to extract data from clinical records. Clinical records of those offenders who had been transferred out of the unit as well as those who were still receiving treatment were included in the study.

\section{Results}

The study identified 42 individuals charged with murder, culpable homicide or for being an accomplice to murder. They included 38 males and 4 females. Their ages ranged from 22 to 66 years with a mean age of 40.7 years. 
Two regions of the country, the Western and Southern provinces accounted for $57.1 \%$ of the sample (Table 1 ). Of the 42 individuals assessed, 37 individuals (88\%) were diagnosed as having a mental illness. Five had a normal mental state and were declared as not having a mental illness.

Among those assessed, $13(30.5 \%)$ were deemed to have been of 'unsound mind' at the time of the alleged offence. This absolved them of criminal responsibility. Twelve individuals $(28.5 \%)$ were found to be of 'sound mind' and therefore could be held responsible for a criminal act despite having a mental illness. No individuals assessed appeared to have feigned symptoms of mental illness. An accurate opinion regarding the person's criminal responsibility could not be arrived at in 13 suspects $(30.5 \%)$ due to the lack of required information.

Among the 37 suspects with a mental illness, 23 $(62.1 \%)$ were diagnosed as having schizophrenia. Other diagnoses were bipolar affective disorder, manic episode (3), unspecified psychotic disorder (3), depression (2), alcohol withdrawal syndrome (1) and intellectual disability (1). The diagnosis of four offenders $(10.3 \%)$ was not mentioned in the report to courts. Of the 23 individuals diagnosed with schizophrenia, nine suspects were deemed to be of 'unsound mind' at the time of the alleged offence. Six suspects were declared to be of 'sound mind' and in eight suspects, the lack of information precluded a determination on the person's criminal responsibility.

\section{Discussion}

This study found that only 13 individuals among 37 mentally ill suspects $(35.1 \%)$ were deemed to be of unsound mind at the time of the alleged offence. A considerable proportion of mentally ill suspects $(32.4 \%)$ were deemed criminally responsible for murder despite having a mental illness at the time of the offence. These findings are similar to those reported from other countries. Sun et al. retrospectively analyzed 105 individuals charged with homicide and found that $34 \%$ were deemed to be responsible for the crime, while $39 \%$ were found to be not responsible (4). In the same study, 28 individuals $(26.7 \%)$ were found

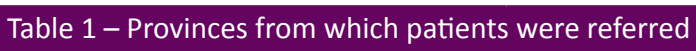

\begin{tabular}{|ll|}
\hline Province & Number \\
\hline Western & 13 \\
Southern & 11 \\
Northwestern & 6 \\
Uva & 4 \\
Sabaragamuwa & 4 \\
Central & 2 \\
Northcentral & 1 \\
Nothern & 1 \\
Easten & 0 \\
\hline
\end{tabular}

to have diminished responsibility for murder, a state of mind not recognized in the penal code of Sri Lanka (4).

A definite opinion regarding criminal responsibility could not be arrived at in almost a third of the suspects referred for a psychiatric opinion. In the majority of them, the mental state at the time of the alleged offence could not be reconstructed because of the delay in referring the accused for assessment. In others, there was a lack of reliable information related to the offence.

The finding that the schizophrenia is the commonest diagnosis among those charged with murder has also been reported by Mafullul et al. where 24\% of the suspects had a diagnosis of schizophrenia (5).

The main limitation of the study was that it was conducted in a single centre, thereby increasing the possibility of a less representative sample.

\section{Conclusions}

Psychiatric assessments found that $35 \%$ of mentally ill persons charged with murder, culpable homicide or for being an accomplice to murder were of unsound mind at the time of the alleged offence. It is important that persons with a suspected mental illness are referred for psychiatric assessment as soon as possible. Delays will limit the psychiatrist's ability to express an opinion regarding the person's criminal responsibility.

\section{Declaration of interest \\ None}

\section{Neil Fernando,}

Consultant Psychiatrist, Angelo De Alwis

Senior Registrar in Forensic Psychiatry,

\section{Wajantha Kotalawala}

Registrar in Psychiatry,

National Institute of Mental Health, Angoda,

Sri Lanka

\section{Corresponding author}

Angelo De Alwis

E mail:angelo.dealwis@gmail.com

\section{References}

1. Legislative enactment of Ceylon. Penal Code [Sri Lanka], Ch; IV, Section 77

2. Hardie T, Elcock S, Mackay RD; Are psychiatrists affecting the legal process by answering legal questions?; Crim Behav Ment Health. 2008;18(2):117-28.

3. Legislative enactment of Ceylon. Penal Code [Sri Lanka], Ch; XVI, Section 296

4. Sun Y,Hu JN; Assessment of criminal responsibility for perpetrators of homicide: analysis of 105 cases; Fa Yi Xue Za Zhi. 2006; 15;22(5):361-4.

5. Mafullul YM, Ogunlesi OA, Sijuwola OA; Psychiatric aspects of criminal homicide in Nigeria; East Afr Med J. 2001;78(1):35-9 